
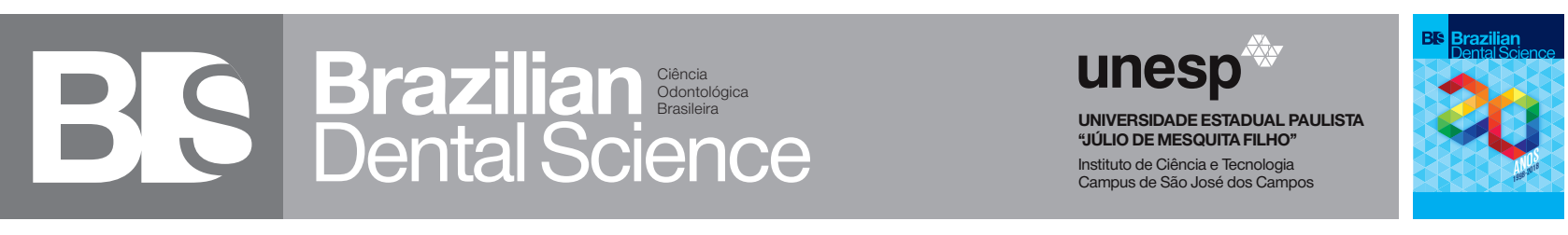

\title{
Influence of illuminants and different observers on the perception of surface gloss of resin composite
}

\author{
Influência de diferentes iluminantes e observadores na percepção do brilho superficial da resina composta
}

Fernanda Bastos Pereira TESSARIN ${ }^{1}$, Laura Célia Fernandes MEIRELLES ${ }^{1}$, Rafael Santos ROCHA ${ }^{1}$, Taciana Marco Ferraz CANEPPELE ${ }^{1}$, Eduardo BRESCIANI ${ }^{1}$

1 - São Paulo State University (Unesp) - Institute of Science and Technology, São José dos Campos - Department of Restorative Dentistry - SP - Brazil.

\section{ABSTRACT}

Objective: To evaluate the visual perception of surface gloss of resin composite under different illuminants by different observers. Material and methods: twelve cylindrical specimens $(6 \mathrm{~mm} \times 1 \mathrm{~mm})$ were fabricated using a nanofilled resin composite (Z350, A2E shade) in order to compare different observers and to determine the limit of perceptibility of surface gloss. Bovine tooth specimen with similar dimensions was obtained for the comparison of different illuminants. Polishing of resin specimens was performed resulting in 6 groups, presenting surface gloss values at 10, $25,40,55,70$, and $85 \mathrm{GU}$ (gloss units), measured by glossmeter (NOVOCURVE). Fifteen individuals were selected: 5 lay-person, 5 undergraduate students, and 5 dental professionals. Participants observed the specimens in a light booth (Gti lightbox) under three different illuminants, and rated the possible combinations between resin specimens or with the bovine enamel specimen (85GU). Data obtained were analyzed by PROBIT non-linear regression analysis $(\alpha=0.05)$. Results: Differences were observed among types of illuminants $(p=0.042)$ and $\Delta G U(p=0.004)$, with no interaction between factors $(p=0.139)$. The fluorescent light presented lower surface gloss perceptibility values in relation to incandescent light. There was no influence by type of observers $(\mathrm{p}=0.598)$. The surface gloss perception limit was 17.6 GU under the presented tested conditions. Conclusion: the illuminant type influenced perception of gloss, with lower percentage of perceptibility for fluorescent light, while such perceptibility was not influence by different observers.

\section{KEYWORDS}

Illuminants; Observer variation; Composite resins; Surface gloss.

\section{RESUMO}

Objetivo: Avaliar a percepção visual e táctil do brilho superficial da resina composta sob diferentes iluminantes e por diferentes observadores. Material e métodos: foram utilizados doze espécimes cilindricos $(6 \mathrm{~mm} \times 1 \mathrm{~mm})$ fabricados em resina composta nanoparticulada (Z350, 3M ESPE- cor A2E) para comparar diferentes observadores e determinar o limite de perceptibilidade do brilho superficial. Um espécime em dente bovino com dimensões similares foi obtido para a comparação de diferentes iluminantes. O polimento do espécime de resina foi realizado, resultando em 6 grupos $(\mathrm{n}=2)$, apresentando valores de brilho superficial em 10, 25, 40, 55, 70 e 85 UB (unidades de brilho), medido por um medidor de brilho (NOVOCURVE Rhopoiny TM, East Sussex, Inglaterra). Foram selecionados quinze indivíduos : 5 leigos, 5 alunos de graduação e 5 profissionais de odontologia. Os participantes observaram espécimes em uma cabine de luz (Gti lightbox, New Jersey, USA), sob três iluminantes diferentes, e avaliaram as possíveis combinações entre espécimes de resina ou com espécime de esmalte bovino (85 UB). Resultados: os dados obtidos foram analisados por análise de regressão não-linear PROBIT (5\%). As diferenças foram observadas entre os tipos de iluminantes $(p=0,042)$ e $\Delta U B(p=0,004)$, sem interação entre os fatores $(\mathrm{p}=0,139)$. A luz fluorescente apresentou valores de percepção de brilho da superfície inferior em relação á luz incandescente. Não houve influência pelo tipo de observadores $(p=0,598)$. O limite de percepção do brilho superficial foi de 17,6 UB sob as condições testadas apresentadas. Conclusão: o tipo de iluminante influenciou na percepção do brilho, com menor porcentagem de perceptibilidade para luz fluorescente $(p=0,042)$, enquanto que a perceptibilidade não foi influenciada pelos diferentes observadores.

\section{PALAVRAS-CHAVE}

Iluminantes. Variações dependentes do observador; Resinas compostas; Brilho superficial. 


\section{INTRODUCTION}

$\mathrm{R}$ esin composites are widely used as the material of choice in direct restorations, supported in part by esthetics demanded by patients [1]. Resin composite restorations should present surface smoothness similar to natural enamel, not resulting in changes for patient satisfaction, biofilm retention, and/or restoration discoloration $[2,3]$. Considering professional aspects, the success of esthetic dental treatment involves functional, morphological, and optical parameters. .

Among the optical properties, the assessment of surface gloss in Dentistry is very important [4,5], since it might be related in a long-term to chemical or mechanical structure deterioration of such materials [6-8]. That fact would possibly lead to optical mismatch between restorative materials and tooth structure, demanding clinical procedures such as restoration repolishing, repairing, or even replacement [9].

Surface gloss is defined as the amount of reflected light in a determined angle, in relation to the amount of incident light [10]. The surface gloss of the materials is not only resultant from the characteristics of materials and the surface quality, but its perception is also influenced by type the of illuminants and the subjectivity/education of the observers [10-12].

The dental literature is vast regarding studies on color of restorative materials. However, according to the Commission Internationale de I'Ecalirage (CIE) [13], the determination of optical properties should not be solely related to color, but other properties such as surface gloss must be also considered.

It is reported that surface gloss of restorative dental materials is often assessed regarding different polishing protocols [14-16]. However, data regarding subjective perception of gloss by patients and dentists is lacking. Thus, determining surface gloss perception by different observers, under different source illuminants, with different characteristics of dental materials (opacity, thickness, and color), would be important to improve protocols and techniques related to direct or indirect esthetic procedures.

The purpose of this study was to evaluate the visual perception of observers (laypeople, undergraduate students and dental professionals) on the surface gloss of resin composite, under different source illuminants, and to determine the limit of perceptibility of gloss using the proposed conditions. The null hypotheses tested were that 1 ) the type of illuminant does not influence the perception of surface gloss of resin composite; and 2) that the different observers do not influence the perception of the surface gloss of resin composite.

\section{MATERIAL AND METHODS}

Twelve cylindrical specimens were fabricated using a nanofilled resin composite (Filtek Z350XT - shade A2E, 3M- ESPE, St.Paul, Mn, USA), using a biparted metallic matrix presenting orifices with $6 \mathrm{~mm}$ in diameter and $1 \mathrm{~mm}$ in thickness. The material was inserted into the orifice in a single increment, covered with a polyester strip and pressed with a glass slide. Resin composite was further light activated for $40 \mathrm{~s}$, using a LED light (Radii - Cal / SDI, Bayswater, Australia) at $900 \mathrm{~mW} / \mathrm{cm}^{2}$, assessed by a radiometer.

\section{Polishing and Gloss assessment}

Resin specimens received initial polishing with sandpaper \#1200 and \#2400 (Fepa-P, Extec, Enfield, CT, USA), for 30 seconds each, coupled to a circular polisher (DP-10, Panambra, São Paulo, SP, Brazil), under water cooling. A metallic device was used during polishing for obtaining a flat and uniform surface.

After the initial polishing, specimens received different polishing protocols using \#1200, \#2400 and/or \#4000 sandpapers according to final surface gloss to be achieved. Specimens with $10 \mathrm{GU}$ were hand polished in 
\#1200 sandpaper with 1 circular movement (resembling a number 8), hold by the thumb. Specimens with 25 GU received similar polishing protocol as $10 \mathrm{GU}$ specimens, except for the number of movements (two circular movements). For group $40 \mathrm{GU}$, one hand circular movement was performed on each sandpaper (\#1200 and \#2400). Specimens with 55 GU received 7 hand circular movements on \#2400 sandpaper. Specimens presenting 70 GU received one hand circular movement on \#2400 sandpaper and 2 hand movements on \#4000 sandpaper. Specimens with 85 GU were polished for 30 seconds with \#4000 sandpaper, using the metallic device. Gloss of specimens, after each polishing protocol, was assessed using the Novo Curve device, with square area of $2 \mathrm{~mm} \mathrm{X} 2 \mathrm{~mm}$ and $60^{\circ}$ of geometry (light incidence), being values expressed in gloss units (GU).

Specimens were submitted to ultrasonic cleaning in distilled water for 5 minutes between each sand paper polishing and also after the final polishing. After the final cleaning, the surface gloss was reassessed.

\section{Bovine enamel specimen}

One bovine enamel specimen was obtained from a bovine incisor, using a trephine diamond bur with internal diameter of $6 \mathrm{~mm}$, coupled to a circular cutting machine (Labcut, Extec, Enfield, CT, USA). Dentin was removed during polishing, resulting in a $1 \mathrm{~mm}$ thick specimen. The final surface gloss was set at $85 \mathrm{GU}$ for further comparisons. Polishing was performed using \#1200, \#2400 and/or \#4000 sandpapers, for 30 seconds in the first two grits and 120 seconds in the last grit.

\section{Selection of observers}

The present research was approved by the local Institutional Review Board (\#1.419.233), and fifteen observers were selected: 5 laypeople, 5 undergraduate dental students, and 5 dentists. Participants' age ranged from 18 to 48 years. They were included after the written consent was signed.
For participation, observers could not present any visual limitation, detected using the Snellen visual graph. Participants should have presented visual correction near to $10 / 10$ (or $10 / 3$ on the metric scale). This means participants should visualize at least $80 \%$ of letters in line 10, at a distance of 3 meters from the graph. The participants were also questioned about the stereoscopic vision, reporting possible differences in vision between the two eyes, which was expected to be normal [12].

\section{Influence of illuminants on gloss perception}

For assessing the influence of different illuminants, specimens (10GU, 25GU, 40GU, 55GU, 70GU, and 85GU), were individually arranged in the light both (Gti lightbox, New Jersey, USA), one at a time, aside with the bovine enamel specimen, in a random sequence for each observer (www.sealedenvelope.com). The comparison of resin composite with enamel specimen intended to be as close as possible to a clinical scenario. Specimens were positioned allowing light incidence angle of $60^{\circ}$. Observers also evaluated the surface gloss at a light reflection angle of $60^{\circ}$ [10-12] (Figure 1).

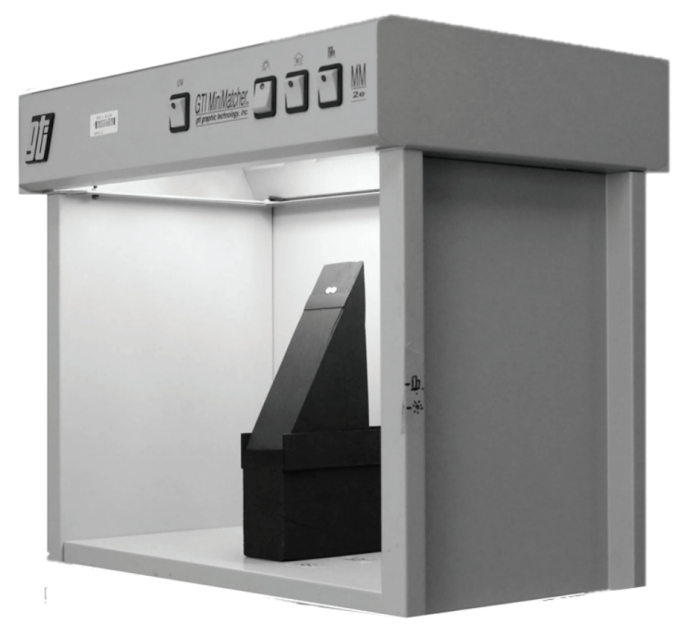

Figure 1 - Representative image in lateral aspect of the light booth, with device positioned for sample disposition.

Observers performed six random observations of the above-mentioned combinations per illuminant, totaling eighteen 
observations considering all illuminants (D65 - daylight, A - 1 incandescent light and F fluorescent light). Observers pointed possible differences in surface gloss within each group of comparisons, indicating which specimen presented greater surface gloss, in case differences were detected. Such information was collected from the answer of the following questions: 1 Do both specimens present same surface gloss? 2 - In case of a negative answer, which one presents greater surface gloss? Affirmative and negative answers were noted for data analyses.

Influence of observers on gloss perception and determining the limit of gloss perceptibility

For such analyses (influence of observers and determining the limit of perceptibility), observers compared resin specimens among them under the D65 illuminant, resulting in possible combinations of GU variations $(\Delta \mathrm{GU})$. $\Delta \mathrm{GU}$ at 15 was obtained comparing $10 \mathrm{GU}$ vs $25 \mathrm{GU}, 25 \mathrm{GU}$ vs $40 \mathrm{GU}, 40 \mathrm{GU}$ vs $55 \mathrm{GU}, 55$ $\mathrm{GU}$ vs $70 \mathrm{GU}$, and $70 \mathrm{GU}$ vs $85 \mathrm{GU}$. $\Delta \mathrm{GU}$ at 30 was assessed evaluating $10 \mathrm{GU}$ vs $40 \mathrm{GU}$, $25 \mathrm{GU}$ vs $55 \mathrm{GU}, 40 \mathrm{GU}$ vs $70 \mathrm{GU}$, and $55 \mathrm{GU}$ vs $85 \mathrm{GU}$. Comparing $10 \mathrm{GU}$ vs $55 \mathrm{GU}, 25 \mathrm{GU}$ vs $70 \mathrm{GU}$, and $40 \mathrm{GU}$ vs $85 \mathrm{GU}$ obtained data regarding $45 \Delta \mathrm{GU}$. $\Delta \mathrm{GU}$ at 60 compared $10 \mathrm{GU}$ vs $70 \mathrm{GU}$, and $25 \mathrm{GU}$ vs $85 \mathrm{GU}$. Specimens were arranged in the light booth (Gti lightbox, New Jersey, USA) following a random list generated in specific website (www.sealedenvelope.com). Observers classified gloss of specimens by answering the previously mentioned questions within the illuminant section.

Data regarding the influence of illuminants and observers were submitted to non-linear regression Probit Model $(\alpha=.05)$ [17], which presents the binary response as dependent variable (affirmative and negative answer on surface gloss assessment), and independent variables being different illuminants or different observers, and gloss variation between specimens.

The limit of perceptibility for surface gloss was determined by non-linear estimation
Probit, taking into account the value in which more than $50 \%$ of observers detect differences [17-19].

\section{RESULTS}

The percentage of right answers regarding differences in surface gloss under different illuminants (resin specimens compared to enamel specimen with $85 \mathrm{GU}$ ) is presented in Figure 2.

Probit analysis revealed differences for illuminants $(p=0.042)$, and variation of gloss $(\Delta \mathrm{GU}) \quad(\mathrm{p}=0.004)$, with no interaction of factors $(\mathrm{p}=0.139)$.

Overall, the perceptibility under D65 was similar to incandescent and to fluorescent lights. Fluorescent illuminant resulted in lower gloss perceptibility than incandescent light. For $\Delta \mathrm{GU}$ individual comparisons (with grouped individuals), the perceptibility of the set $10 \mathrm{vs}$ $85 \mathrm{GU}$ was similar to 25 vs $85 \mathrm{GU}$ and both revealed higher gloss perceptibility than the other tested combinations. The set 40 vs 85 GU resulted in higher gloss perceptibility compared to the sets 55 vs $85 \mathrm{GU}, 70$ vs $85 \mathrm{GU}$, and 85 vs $85 \mathrm{GU}$, being the last three sets similar among them (Figure 2).

The percentage of gloss perceptibility considering observers (comparisons among resin composite specimens) resulted in differences among gloss variation $(\mathrm{p}<0.001)$, no influence of type of observer $(\mathrm{p}=0.598)$, nor interaction of factors $(\mathrm{p}=0.235)$, according to PROBIT regression analysis. As observers percept gloss similarly, the percentage data of different observers were grouped and are shown in Figure 3.

The limit of perceptibility of gloss variation, defined as the probability of at least $50 \%$ of observers detect gloss differences, was calculated by means of non-linear estimation (Probit) and resulted in $17.6 \Delta \mathrm{GU}$, according to the following regression formula $y=$ inormal $(-0.55312+(0.032329) * x, 0 ; 1)$ represented in the perceptibility curve (Figure 4). 


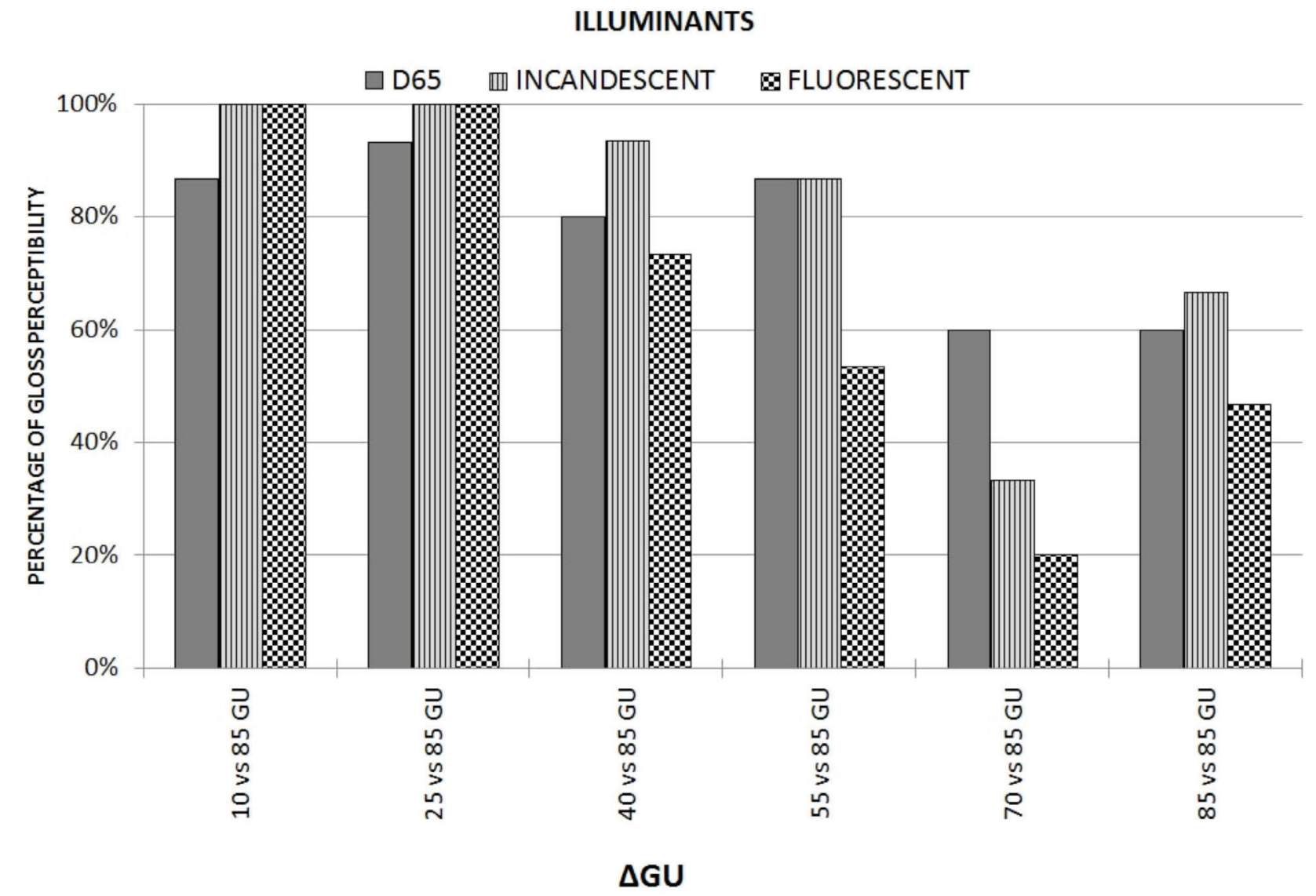

Figure 2 - Percentage of surface gloss perceptibility according to the different tested illuminants: D65, Incandescent, and Fluorescent lights, under different $\Delta \mathrm{GU}$ comparisons. 
ALL OBSERVERS

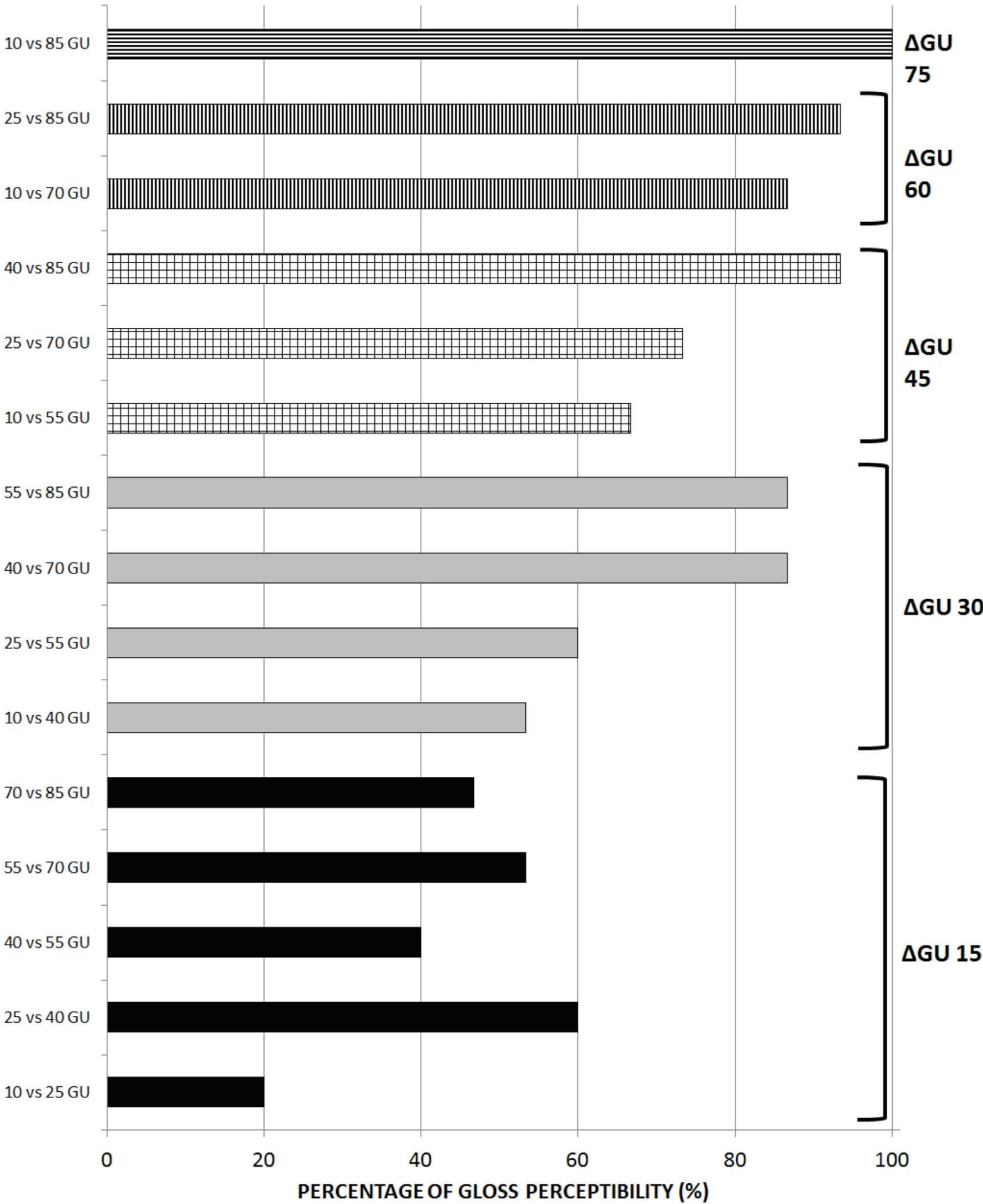

Figure 3 - Percentage of gloss perceptibility for all observers regarding $\Delta$ GU intervals. 


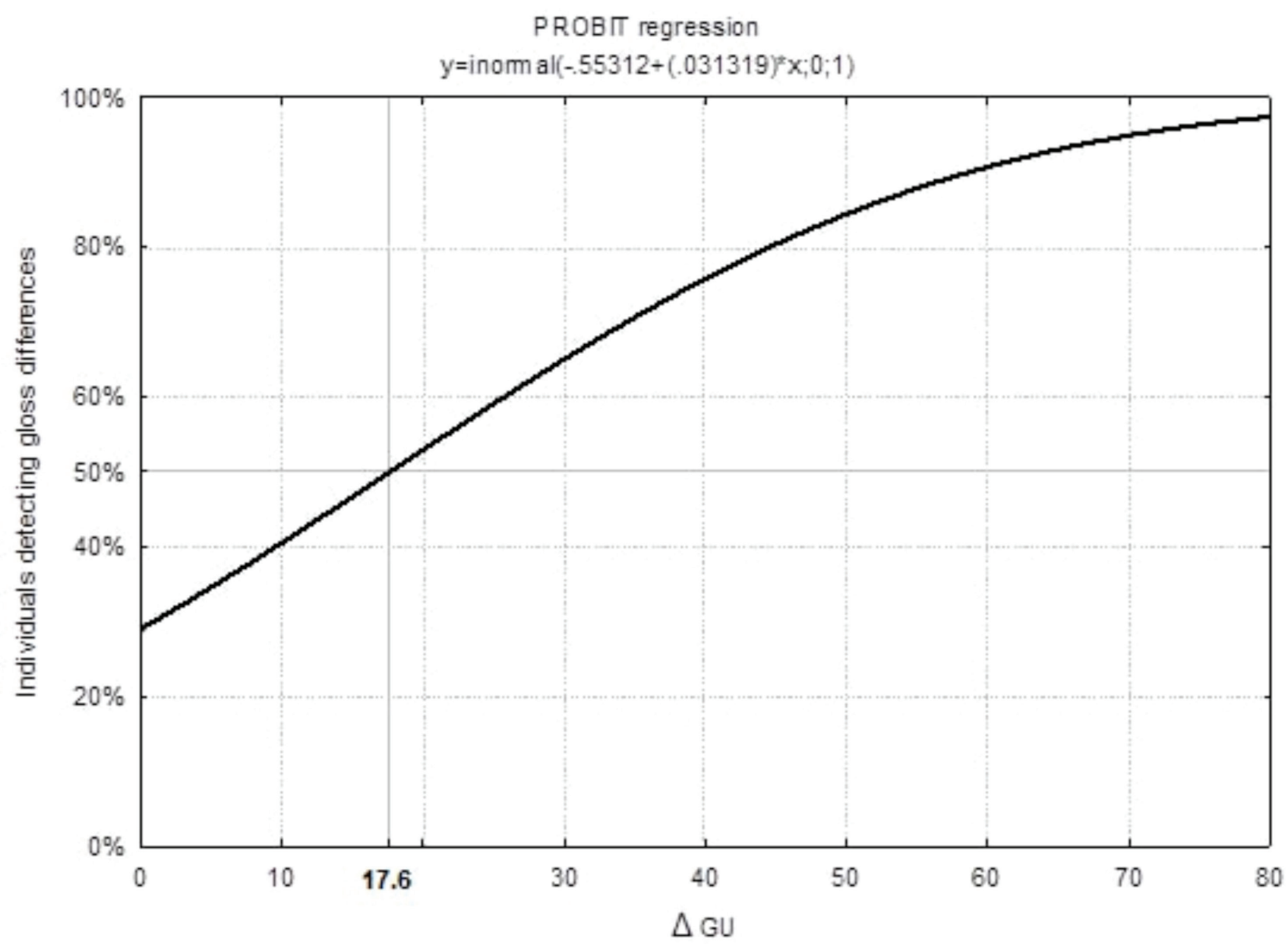

Figure 4 - Non-linear estimate curve and the resulted limit of gloss perceptibility (17.6 $\Delta \mathrm{GU})$.

\section{DISCUSSION}

Considering the several possible influences of surface gloss of restorative materials in Dentistry, the perception of such property (subjective gloss determination) may be of greater importance, once many aspects seem to influence this specific scenario. Determining surface gloss perception in Dentistry is lacking in the literature, being most of researches performed in other fields like psychology, physics, and computer graphics.

The decision to employ non-linear regression statistic analyses for analyzing gloss perception data in the present study is based on the fact the gloss is reported to present a plateau of perception in ranges close to 30 , and $80 \mathrm{GU}$ [18], and using linear regression would hinder proper data manipulation and interpretation. Non-linear protocols allow a proper fit of data presenting such reported characteristics within regression curves.

Differences in gloss perception for different illuminants were detected, and the fluorescent light presented the lowest perceptibility proportions among observers. Thus, the first hypothesis was rejected. Illumination is reported in the literature to influence on the perception of gloss [19]. In studies that glossy spheres are observed under simulated illumination mimicking illumination 
of a kitchen, a grove, or a town, confirmed the influence of different illuminants on gloss perception, and the authors argued the presence of reflective areas are responsible for such finding [20]. Although the same specimens were presently evaluated under the different tested illuminants, the influence of specific lights might have influenced the presence or absence or reflective areas, suggesting the fluorescent light led to lesser reflective areas, and consequently poorer perception in $\Delta G U$. The presence of a mesoestructure, which refers to surfaces presenting peaks and valleys, is also related to improved perception of gloss $[20,21]$. Such information may explain the differences in gloss perception within similar $\Delta \mathrm{GU}$ values, but from different GU combinations (e.g. in Figure 3 , within $\Delta G U$ of 15 , the difference between 25 $\mathrm{GU}$ and $40 \mathrm{GU}$ was more often perceived).

The choice for comparing the three tested illuminants is due to the fact patients are often exposed to such sources, either in Dental clinics or in daily activities, and also to the fact those illuminants are frequently employed in studies assessing their influence on color [22]. The authors are, however, not able to compare studies reporting on color once, although they are reporting properties referred to light reflection, their interaction to dental materials and their responses are somewhat different.

Another consideration in this study is the use of a specimen in bovine enamel. Many observers reported difference between the color of specimens, and such fact might have altered gloss perception [23], possibly interfering with the results found.

For the factor type of observers, no influence on gloss perception was noticed according to the grouping proposed in the present study, accepting the second null hypothesis proposed. It has been reported that non-natural illumination allows greater gloss differentiation [10], while observing under natural illumination, representing the real world, results in similarity of gloss perception by observers. Considering such information for the present results, no difference would be also expected under natural lighting.

Moreover, none of the present observers were educated according to surface gloss, and it is known [10] if observers are informed on which to look at (shape, reflection and contrast areas, among others), they are able to better define gloss in real world conditions.

The lack of observer influence might be related to several supposed conditions: the non-Dental related group might have been previously exposed to gloss scenarios, once they are not exclusive to the Dental field; by limiting the visualization angle, the detection of reflection areas might have been facilitated; the flat and even surface of specimens might have simplified the detection of gloss; the lack of contrast on the surface of tested specimens and the lack of mesoestrucures might have led to a more uniform gloss detection; and finally, the presence of black backing and black surrounding environment might have aided greater perception in gloss differences.

In a study, in which freedom for observing the surface gloss of objects was allowed [24], the authors concluded those observers detect gloss with greater reliability, possibly by the interaction with objects and encouraged visual exploration. In the present research, we assume a different gloss perception would have been detected with free visualization[24], with a possible influence on observer groups, once by fixing the visualization angle one could have helped observers finding the reflective areas of specimens, especially in the lay-person group.

Gloss detection among gloss variations reveals easier detection for larger $\Delta G U$, in which $100 \%$ of observers detected a $\Delta \mathrm{GU}$ of 75 , while 
about $45 \%$ detected a $\Delta G U$ of 15 . We should also point out the difference in gloss detection for $\Delta \mathrm{GU}$ of 15 , considering the comparison of 25 vs $40 \mathrm{GU}, 30$ vs $45 \mathrm{GU}$, in contrast to 70 vs $85 \mathrm{GU}$. This fact might be explained by a linear break in the gloss scale with values close to 30 and $80 \mathrm{GU}$ [18]. Thus, specimens presenting gloss values just under or above 30 or $80 \mathrm{GU}$, present easier detectable gloss differences, confirmed by the $60 \%$ perceptibility during the comparison between 24 and $40 \mathrm{GU}$. On the other hand, it is also interesting to note the almost complete lack of perceptibility when comparing 10 vs 25 GU specimens, fact supported by a drastic reduction of gloss for values under $20 \mathrm{GU}$ [18].

Regarding the limit of gloss perceptibility, the value defined by the nonlinear estimate regression was 17.6 GU. This means that within the assessed conditions of the present study, if a difference in surface gloss greater than $17.6 \mathrm{GU}$ is present, at least $50 \%$ of the observers will detect such differences. There is no reference in the Dental literature to compare and/or discuss the referred information regarding $\Delta G U$ limit of perceptibility. The authors should highlight that specimens with different characteristics may influence and result in different observations, being a limitation of the present study. The idea behind determining the limit of gloss perceptibility in resin composites is based on the limit of color perceptibility previously determined, being defined in the literature as a $\Delta \mathrm{E}$ from 1.0 to $3.7[25,26]$.

The perception of gloss in Dentistry is important for defining adequate polishing protocols, deterioration of restorations under use, and to determine the reflection areas, especially in esthetic scenarios $[27,28]$. Such considerations base the importance of the present study.

Limitations as selection of observers, the interval of studied gloss, and also the comparison of different substrates for the illuminant analysis, should be cited.

We conclude the illuminant type influenced perception of gloss, with lower percentage of perceptibility for fluorescent light, while such perceptibility was not influence by different observers.

\section{ACKNOWLEDGEMENT}

This investigation was supported by São Paulo Research Foundation (FAPESP), Scholarship \#2015/07764-1.

\section{REFERENCES}

1. Demarco FF,Collares K, Coelho-de-Souza FH, Correa MB, Cenci MS, Moraes $\mathrm{RR}$, et al. Anterior composite restorations: A systematic review on long-term survival and reasons for failure. Dent Mater. 2015;31(10):1214-24.

2. Antonson SA, Yazici AR, Kilinc E, Antonson DE, Hardigan PC. Comparison of different finishing/polishing systems on surface roughness and gloss of resin composites. JDent. 2011;39 Suppl 1:e9-17.

3. Aykent F, Yondem I, Ozyesil AG, Gunal SK, Avunduk MC, Ozkan S. Effect of different finishing techniques for restorative materials on surface roughness and bacterial adhesion. The Journal of prosthetic dentistry. 2010;103(4):221-7.

4. Da Costa J, Ferracane J, Paravina RD, Mazur RF, Roeder L. The effect of different polishing systems on surface roughness and gloss of various resin composites. JEsthet Restor Dent. 2007;19(4):214-24; discussion 25-6.

5. Kaizer MR, de Oliveira-Ogliari A, Cenci MS, Opdam NJ,Moraes RR. Do nanofill or submicron composites show improved smoothness and gloss? A systematic review of in vitro studies. Dent Mater.2014;30(4):e41-78.

6. Salgado VE, Cavalcante LM, Silikas N, Schneider LF. The influence of nanoscale inorganic content over optical and surface properties of model composites. J Dent. 2013;41Suppl 5:e45-53.

7. Valente LL, Peralta SL, Ogliari FA, Cavalcante LM, Moraes RR. Comparative evaluation of dental resin composites based on micron- and submicron-sized monomodal glass filler particles. Dent Mater. 2013;29(11):1182-7.

8. Ardu S, Braut V, Uhac I, Benbachir N, Feilzer AJ, Krejci I Influence of mechanical and chemical degradation on surface gloss of resin composite materials. Am J Dent. 2009;22(5):264-8.

9. Palaniappan S, Elsen L, Lijnen I,Peumans M, Van Meerbeek B, Lambrechts P. Three-year randomised clinical trial to evaluate the clinical performance, quantitative and qualitative wear patterns of hybrid composite restorations. Clin Oral Investig. 2010;14(4):441-58.

10. Chadwick AC, Kentridge RW. The perception of gloss: a review. Vision research. 2015;109:221-35.

11. Schmid AC, Anderson BL. Do surface reflectance properties and 3-D mesostructure influence the perception of lightness? JVis. 2014;14(8):24.

12. Ged G, Obein G, SilvestriZ, Le Rohellec J, VienotF. Recognizing real materials from their glossy appearance. J Vis. 2010;10(9).

13. Comission Internacionale de l'Ecalirage (CIE). A Framework for the meansurement of visual appearance.CIE:175.2006. 
14. Kamonkhantikul K, Arksornnukit M, Takahashi H, Kanehira M, Finger WJ. Polishing and toothbrushing alters the surface roughness and gloss of composite resins. Dent Mater J. 2014;33(5):599-606.

15. Hosoya Y, Shiraishi T,Odatsu T, Nagafuji I, Kotaku M, Miyazaki M, Powers JM. Effects of polishing on surface roughness, gloss, and color of resin composites. J Oral Sci. 2011;53(3):283-91.

16. Waheeb N, Silikas N, Watts D. Initial polishing time affects gloss retention in resin composites. Am JDent. 2012;25(5):303-6.

17. Douglas RD, Steinhauer TJ, Wee AG. Intraoral determination of the tolerance of dentists for perceptibility and acceptability of shade mismatch. J Prosthet Dent. 2007;97(4):200-8.

18. Ji W, Pointer MR, Luo RM, Dakin J. Gloss as an aspect of the measurement of appearance.J Opt Soc Am A Opt Image Sci Vis. 2006 Jan;23(1):22-33.

19. Olkkonen $\mathrm{M}, \mathrm{Brainard} \mathrm{DH}$. Perceived glossiness and lightness under real-world illumination. J Vis. 2010;10(9):5.

20. Marlow PJ, Anderson BL. Generative constraints on image cues for perceived gloss. JVis. 2013;13(14).

21. Marlow PJ, Kim J, Anderson BL. The perception and misperception of specular surface reflectance. Curr Biol. 2012;22(20):1909-13.
22. Lee YK, Yu B, Lim JI, Lim HN. Perceived color shift of a shade guide according to the change of illuminant. JProsthet Dent. 2011;105(2):91-9.

23. Barucci-Pfister N, Gohring TN. Subjective and objective perceptions of specular gloss and surface roughness of esthetic resin composites before and after artificial aging. Am J Dent. 2009;22(2):102-10.

24. Scheller Lichtenauer M, SchuetzP,Zolliker P.Interaction improves perception of gloss. JVis. 2013;13(14).

25. Paravina RD, Ghinea R, Herrera LJ, Bona AD, Igiel C, Linninger M, Sakai M Takahashi H, Tashkandi E, Perez MeM. Color difference thresholds in dentistry. JEsthet Restor Dent. 2015;27 Suppl 1:S1-9.

26. Khashayar G, Bain PA, Salari S, Dozic A, Kleverlaan CJ, Feilzer AJ. Perceptibility and acceptability thresholds for colour differences in dentistry.J Dent 2014;42(6):637-44.

27. Heymann HO. The artistry of conservative esthetic dentistry.J Am Dent Assoc. 1987;Spec No:14E-23E.

28. Brezniak N, Wasserstein A, Shmuli T. [Light reflection zone on the incisors' surface--a new parameter for smile esthetics evaluation]. Refu'atha-peh veha-shinayim. 2012;29(3):39-43,57.

\section{Prof. Dr. Eduardo Bresciani}

(Corresponding address)

Instituto de Ciência e Tecnologia, UNESP - Departamento de Odontologia Restauradora

Av. Eng. Francisco José Longo, 777 - São Jose dos Campos, SP, Brasil - 12245-000

Telephone: +55 1239479000 / Fax: +55 1239479010

Date submitted: 2018 Aug 20

E-mail: eduardob@ict.unesp.br 